\title{
Gamma Knife radiosurgery as a primary treatment for central neurocytoma
}

\author{
Chiman Jeon, MD, Kyung Rae Cho, MD, Jung Won Choi, MD, PhD, Doo-Sik Kong, MD, PhD, \\ Ho Jun Seol, MD, PhD, Do-Hyun Nam, MD, PhD, and Jung-II Lee, MD, PhD \\ Department of Neurosurgery, Samsung Medical Center, Sungkyunkwan University School of Medicine, Seoul, Korea
}

\begin{abstract}
OBJECTIVE This study was performed to evaluate the role of Gamma Knife radiosurgery (GKRS) as a primary treatment for central neurocytomas (CNs).

METHODS The authors retrospectively assessed the treatment outcomes of patients who had undergone primary treatment with GKRS for CNs in the period between December 2001 and December 2018. The diagnosis of CN was based on findings on neuroimaging studies. The electronic medical records were retrospectively reviewed for additional relevant preoperative data, and clinical follow-up data had been obtained during office evaluations of the treated patients. All radiographic data were reviewed by a dedicated neuroradiologist.
\end{abstract}

RESULTS Fourteen patients were treated with GKRS as a primary treatment for CNs in the study period. Seven patients (50.0\%) were asymptomatic at initial presentation, and $7(50.0 \%)$ presented with headache. Ten patients $(71.4 \%)$ were treated with GKRS after the diagnosis of CN based on characteristic MRI findings. Four patients (28.6\%) initially underwent either stereotactic or endoscopic biopsy before GKRS. The median tumor volume was $3.9 \mathrm{~cm}^{3}$ (range $0.46-18.1 \mathrm{~cm}^{3}$ ). The median prescription dose delivered to the tumor margin was $15 \mathrm{~Gy}$ (range 5.5-18 Gy). The median maximum dose was $30 \mathrm{~Gy}$ (range 11-36 Gy). Two patients were treated with fractionated GKRS, one with a prescription dose of $21 \mathrm{~Gy}$ in 3 fractions and another with a dose of $22 \mathrm{~Gy}$ in 4 fractions. Control of tumor growth was achieved in all 14 patients. The median volume reduction was $26.4 \%$ (range 0\%-78.3\%). Transient adverse radiation effects were observed in 2 patients but resolved with improvement in symptoms. No recurrences were revealed during the follow-up period, which was a median of 25 months (range 12-89 months).

CONCLUSIONS Primary GKRS for CNs resulted in excellent tumor control rates without recurrences. These results suggest that GKRS may be a viable treatment option for patients with small- to medium-sized or incidental CNs.

https://thejns.org/doi/abs/10.3171/2020.4.JNS20350

KEYWORDS central neurocytoma; Gamma Knife radiosurgery; primary treatment; stereotactic radiosurgery

$\mathrm{F}$ IRST described by Hassoun et al. in 1982, central neurocytomas (CNs) are rare brain tumors generally associated with the septum pellucidum or the wall of the lateral ventricles, accounting for $0.1 \%-0.5 \%$ of all intracranial tumors. ${ }^{1-3}$ Most of these tumors are benign and classified as World Health Organization (WHO) grade II tumors. ${ }^{4-6}$ They tend to affect both children and young adults, with equal prevalence in males and females. ${ }^{1,7}$ They are usually diagnosed when there is blockage of the cerebrospinal fluid pathways, causing hydrocephalus associated with elevated intracranial pressure. ${ }^{8}$ Although CNs can be cured by complete resection, complete removal is often difficult in cases in which the tumors are hypervascular or adhere to the fornix. Only one-third to one-half of patients with CNs are without neurological deficits after complete surgical removal. ${ }^{1,9}$

Given the radiosensitive nature of $\mathrm{CN}$, radiation therapy (RT) has been reported to be effective as adjuvant treatment after incomplete resection of CNs with a high rate of tumor control. ${ }^{1,9-14}$ However, long-term radiationrelated complications have also been reported following RT. ${ }^{11,15-17}$ As an alternative to RT, stereotactic radiosurgery (SRS) has emerged as a minimally invasive adjuvant or primary treatment for CNs. The effectiveness of Gamma Knife radiosurgery (GKRS) for CNs has been reported, with a high rate of tumor control and a low complication rate..$^{12,18-23}$ To our knowledge, a limited number of studies have evaluated the usefulness of SRS as a primary treat-

ABBREVIATIONS CN = central neurocytoma; ED = emergency department; GKRS = Gamma Knife radiosurgery; RT = radiation therapy; SRS = stereotactic radiosurgery. SUBMITTED February 5, 2020. ACCEPTED April 9, 2020.

INCLUDE WHEN CITING Published online June 19, 2020; DOI: 10.3171/2020.4.JNS20350. 
ment for CNs. ${ }^{8,12,24,25}$ The goal of this study was to report a single-center experience with GKRS as a primary treatment for CNs.

\section{Methods \\ Patient Population}

This retrospective study included the patients who had undergone GKRS for CNs as a primary treatment between December 2001 and December 2018 at Samsung Medical Center. The diagnosis of $\mathrm{CN}$ was based on findings on neuroimaging studies. ${ }^{26}$ The electronic medical records were retrospectively reviewed for additional relevant preoperative data. This study was approved by the institutional review board of Samsung Medical Center.

\section{Volumetric Analysis for Tumor Response}

Clinical follow-up data had been obtained during office evaluations of the patients after GKRS. Gadoliniumenhanced T1-weighted images were imported into Leksell GammaPlan software (version 11.0.3, Elekta Instrument AB) for assessment of changes in tumor volume. Both initial and last follow-up tumor volumetry were determined using the functionality included in the software. Based on the last available MR images, tumor responses were classified into two different categories: tumor control (a decrease of $>15 \%$ volume [decreased] or follow-up volume $\pm 15 \%$ of the initial volume [stable]) or tumor progression (an increase of $>15 \%$ volume). ${ }^{27-29}$ All radiographic data were reviewed by a dedicated neuroradiologist.

\section{Radiosurgical Technique}

The GKRS procedure was performed using Leksell Gamma Knife Perfexion and Icon (Elekta Instrument $\mathrm{AB}$ ), and Leksell GammaPlan was used for treatment planning. At our institution, all patients received $5 \mathrm{mg}$ dexamethasone intravenously immediately before the procedure and completed a 7-day course of dexamethasone following the procedure. For each patient, early morning on the first day of GKRS, the stereotactic Leksell G-frame was placed by the treating neurosurgeon after infiltration of local anesthetics. Following frame placement, high-resolution stereotactic MRI was performed. Axial postcontrast T1-weighted images with a slice thickness of $1.0 \mathrm{~mm}$ and T2-weighted images with a slice thickness of $2.0 \mathrm{~mm}$ were obtained for treatment planning. For those undergoing frameless SRS using Gamma Knife Icon, the patients were immobilized using a thermoplastic mask system consisting of customized 3-point Efficast thermoplastic masks (Orfit Industries) and cradles (Moldcare, Alcare Co. Ltd.). After high-resolution MRI had been performed on the day before frameless GKRS, a planning cone beam CT was subsequently performed and coregistered with MR images for target localization and verification. Given the increased risk of radiation-induced necrosis for large lesions, frameless fractionated GKRS was performed for the patients with CNs greater than $10 \mathrm{~cm}^{3}$ in volume (cases 10 and 13). ${ }^{30}$ Dose planning was performed and approved by the treating neurosurgeon in conjunction with a medical physicist.

\section{Results}

\section{Patient and Tumor Characteristics}

A total of 14 patients were treated with GKRS as a primary treatment for CNs during the study period (Table 1). There were 5 women $(35.7 \%)$ and 9 men (64.3\%). The median age was 38.5 years (range $27-59$ years). Seven patients $(50.0 \%)$ were asymptomatic at initial presentation, and 7 patients $(50.0 \%)$ presented with headache. The most common tumor location was the lateral ventricle (11 patients [78.6\%]), followed by the third ventricle (3 patients [21.4\%]). Ten patients $(71.4 \%)$ were treated with GKRS after the diagnosis of $\mathrm{CN}$ based on characteristic MRI findings. Before GKRS, 4 patients (28.6\%) had initially undergone either image-guided stereotactic or endoscopic biopsy, after which the diagnosis of $\mathrm{CN}$ was pathologically confirmed. One patient was found to have hydrocephalus at the time of diagnosis and underwent endoscopic biopsy following endoscopic third ventriculostomy. Patients were followed up for a mean of 38.6 months and a median of 25 months (range 12-89 months).

The median $\mathrm{CN}$ volume was $3.9 \mathrm{~cm}^{3}$ (range $0.46-18.1$ $\left.\mathrm{cm}^{3}\right)$. The median prescription dose delivered to the tumor margin was 15 Gy (range 5.5-18 Gy). Two patients were treated with fractionated GKRS, one with a prescription dose of 21 Gy in 3 fractions and another with a dose of 22 Gy in 4 fractions. The median maximum dose was 30 Gy (range 11-36 Gy). Dose plans involved a multiisocentric technique; the median number of isocenters used was 13.5 (range 4-27).

\section{Tumor Response and Change in Symptoms}

Tumor control following GKRS was achieved in all 14 patients (Table 2): tumors were decreased in volume in 11 patients and stable in 3 patients at the last follow-up (Figs. 1 and 2A-F). The median volume reduction was $26.4 \%$ (range 0\%-78.3\%). Among the 7 patients who had presented with headache before GKRS, improvement in symptoms was observed in 6 , while intermittent headache persisted in 1 patient despite GKRS treatment. None of the patients in this series had developed hydrocephalus or additional symptoms at the last follow-up.

\section{Adverse Radiation Effect After GKRS}

Two of the 14 patients (14.3\%) experienced adverse radiation effects 3 months after GKRS. One patient (case 12) presented to the emergency department (ED) with severe headache, and MRI showed that the treated lesion had increased in size compressing the foramen of Monro with enlargement of the ipsilateral lateral ventricle (Fig. 2H). Dexamethasone was immediately administered, and the patient was hospitalized for 7 days, after which his symptom greatly improved. Tumor shrinkage $(24.7 \%$ reduction in volume) was observed at the 12-month follow-up without additional symptoms. The other patient (case 14) also presented to the ED with progressive headache, and MRI revealed an enlarged tumor without a change in the size of the lateral ventricle (Fig. 2K). She was managed immediately with the administration of dexamethasone and was discharged after 4 days with improvement in her symptom. The tumor decreased in size by $36 \%$ by the 12 -month follow-up. 
TABLE 1. Characteristics of the 14 patients treated with primary GKS for central neurocytomas

\begin{tabular}{|c|c|c|c|c|c|c|c|c|c|}
\hline Case No. & Sex/Age (yrs) & Sx & Tumor Location & Preop HCP & Biopsy & Tumor Vol $\left(\mathrm{cm}^{3}\right)$ & GKS & Max Dose (Gy) & Margin Dose (Gy) \\
\hline 1 & $M / 52$ & $\mathrm{HA}$ & TV & Yes & Yes & 0.46 & Single & 32 & 16 \\
\hline 2 & $\mathrm{~F} / 27$ & $\mathrm{HA}$ & LV & No & Yes & 7.8 & Single & 32 & 16 \\
\hline 3 & $M / 36$ & None & LV & No & No & 6.6 & Single & 30 & 15 \\
\hline 4 & $M / 38$ & $\mathrm{HA}$ & LV & No & No & 3.7 & Single & 28 & 14 \\
\hline 5 & $\mathrm{M} / 40$ & None & LV & No & No & 0.47 & Single & 36 & 18 \\
\hline 6 & $M / 39$ & $\mathrm{HA}$ & LV & No & No & 6.6 & Single & 28 & 14 \\
\hline 7 & $\mathrm{~F} / 41$ & None & LV & No & No & 0.63 & Single & 34 & 17 \\
\hline 8 & $\mathrm{~F} / 58$ & $\mathrm{HA}$ & TV & No & Yes & 2.7 & Single & 36 & 18 \\
\hline 9 & $M / 29$ & $\mathrm{HA}$ & TV & No & No & 3.8 & Single & 30 & 15 \\
\hline 10 & $M / 34$ & $\mathrm{HA}$ & LV & No & Yes & 13.9 & Fraction & 14 & $7(3)^{*}$ \\
\hline 11 & $M / 34$ & None & LV & No & No & 3.9 & Single & 30 & 15 \\
\hline 12 & $\mathrm{M} / 59$ & None & LV & No & No & 8.9 & Single & 28 & 14 \\
\hline 13 & $F / 34$ & None & LV & No & No & 18.1 & Fraction & 11 & $5.5(4)^{*}$ \\
\hline 14 & $\mathrm{~F} / 49$ & None & LV & No & No & 2.5 & Single & 30 & 15 \\
\hline
\end{tabular}

Fraction = fractionation; $\mathrm{HA}=$ headache; $\mathrm{HCP}=$ hydrocephalus; $\mathrm{LV}=$ lateral ventricle; None = incidental finding; $\mathrm{Sx}=$ symptoms; $\mathrm{TV}=$ third ventricle.

* Number in parentheses indicates the number of fractions.

\section{Discussion}

CNs are rare WHO grade II neuronal tumors with a favorable prognosis. ${ }^{13,31,32}$ They tend to be located predominantly in the lateral ventricle near the foramen of Monro and to a lesser extent in the third ventricle. ${ }^{6}$ Complete resection has been the primary treatment for $\mathrm{CN}$; however, complete removal is often difficult when the tumor is hypervascular or deep seated and adheres to the fornix or thalamus. Therefore, the risks of surgery-related morbidity and mortality are not negligible, but some studies have reported the effectiveness of primary SRS for CNs..$^{20,21}$

Before the era of SRS, conventional fractionated RT was a common noninvasive approach used to manage residual or recurrent CNs after resection., ${ }^{2,32}$ The effectiveness of RT for recurrent or residual CNs has been reported with high tumor control rates. ${ }^{14,33}$ However, delayed complications related to RT, such as radiation necrosis, radiation-induced malignant tumor, and leukoencephalopathy, have also been reported, and the radiation-induced toxicity is still being weighed against the benefits of tumor control. ${ }^{9,33-36}$ Given that $\mathrm{CN}$ is a highly vascularized and well-demarcated tumor within the ventricular system, it seems to be an ideal target for SRS because dose planning is easier and safer in $\mathrm{CN}$ than in other ill-defined lesions

TABLE 2. Summary of tumor responses and change in symptoms after GKS

\begin{tabular}{|c|c|c|c|c|c|c|c|}
\hline \multirow[b]{2}{*}{ Case No. } & \multicolumn{3}{|c|}{ Tumor Response } & \multirow[b]{2}{*}{ Change in $S x^{*}$} & \multirow[b]{2}{*}{ ARE } & \multicolumn{2}{|c|}{$\mathrm{FU}$ (mos) } \\
\hline & 12 Mos & 24 Mos & Last FU & & & Radiological & Clinical \\
\hline 1 & Decreased & Stable & Stable & Improved & - & 83 & 89 \\
\hline 2 & Decreased & Decreased & Stable & Improved & - & 67 & 71 \\
\hline 3 & Decreased & Decreased & Stable & Asymptomatic & - & 88 & 89 \\
\hline 4 & Decreased & Decreased & Stable & Intermittent HA & - & 72 & 75 \\
\hline 5 & Stable & NA & Stable & Asymptomatic & - & 26 & 26 \\
\hline 6 & Decreased & Stable & Stable & Improved & - & 46 & 48 \\
\hline 7 & Stable & NA & Stable & Asymptomatic & - & 22 & 23 \\
\hline 8 & Decreased & NA & Stable & Improved & - & 25 & 33 \\
\hline 9 & Decreased & Stable & & Improved & - & 24 & 24 \\
\hline 10 & Decreased & & & Improved & - & 12 & 13 \\
\hline 11 & Stable & & & Asymptomatic & - & 12 & 12 \\
\hline 12 & Decreased & & & Asymptomatic & + & 12 & 13 \\
\hline 13 & Decreased & & & Asymptomatic & - & 12 & 12 \\
\hline 14 & Decreased & & & Asymptomatic & + & 12 & 12 \\
\hline
\end{tabular}

ARE = adverse radiation effect; FU = follow-up; NA = not applicable; - = absent; + = present.

*Symptoms at last follow-up were recorded. 


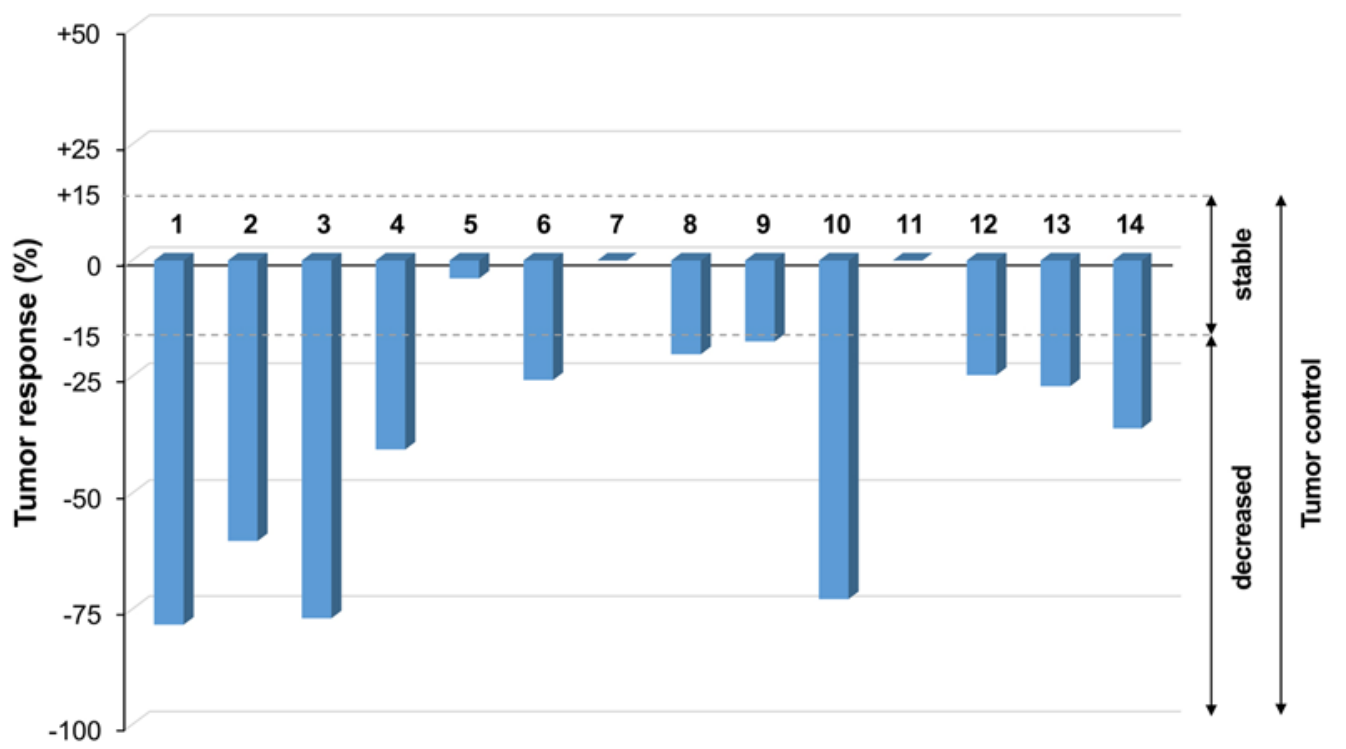

FIG. 1. Tumor response to GKRS as assessed by relative change in volume between pretreatment and the last follow-up MRI. Figure is available in color online only.

located in the brain parenchyma. ${ }^{31}$ SRS potentially avoids the long-term side effects related to conventional RT with its rapid dose decrease at the target edges and local control of tumor growth. ${ }^{18}$ Since Schild et al. first reported on residual CN treated with GKRS, most studies in the literature have demonstrated favorable radiosurgical outcomes using GKRS or linear accelerator for residual or recurrent CNs. ${ }^{1,8,9,16-19,22,23,25,31,33,34,37-41}$ A systematic quantitative review by Park and Steven first revealed that single-session SRS is a safe and effective treatment option for recurrent or residual CNs, with a $91.1 \%$ estimated cumulative rate of tumor control..$^{34}$

In the literature, 8 studies on primary GKRS for $\mathrm{CN}$ have reported an overall total of 39 cases, including those in the present series (Table 3). ${ }^{8,9,12,25,37,38,42}$ Based on radiological findings, Kim et al. described 6 of 13 cases in which CNs were treated with GKRS without confirmation of histology. ${ }^{12}$ All tumors in the 6 patients were decreased in size after primary GKRS without recurrences during a median follow-up of 42 months. The authors subsequently reported on their series with additional patients and a longer followup, for a total of 10 patients treated with GKRS alone. ${ }^{9}$ Among these 10 patients, tumor control was achieved in 8 without complications. Karlsson et al. performed a multicenter study to analyze the outcome of 42 patients with CNs, including 7 patients who received GKRS alone as primary treatment. ${ }^{8}$ No recurrences were observed among these 7 patients, nor were there permanent complications. These authors found primary GKRS to be effective for managing incidental, asymptomatic CNs, although histological verification of $\mathrm{CN}$ is recommended in most cases. In our series, we performed primary GKRS in 14 patients with CNs, with biopsy confirmation in only 4 cases prior to treatment. All the tumors were controlled with GKRS. No tumor progression was observed during the follow-up period.
Several reports on recurrences after GKRS for recurrent or residual CNs have been published. ${ }^{12,13,20,25} \mathrm{Kim}$ et al. found that patients treated with postoperative GKRS for CNs demonstrated a propensity to show an "out-of-field recurrence" failure pattern. ${ }^{12}$ Yen et al. reported 2 cases of out-of-field recurrence that were difficult to detect even with a retrospective review of the MR images obtained at the time of GKRS. ${ }^{25}$ In contrast, few studies on recurrences after primary GKRS for CNs are available in the literature. Kim et al. observed local tumor control failure in 2 of 10 patients who had received GKRS as a primary treatment for $\mathrm{CN} .{ }^{9}$ One patient underwent repeat GKRS for tumor progression after initial treatment with GKRS, while another patient was followed up with close observation after the irradiated lesion was found to have increased with cystic enlargement. In our study, no recurrences were observed in the 14 patients with CNs after treatment with GKRS during a median follow-up period of 25 months. Moreover, no patients developed distant recurrences or dissemination along the craniospinal axis after GKRS. Careful observation with long-term MRI follow-up after GKRS is warranted.

In a systemic review of 218 patients by Pan and Lee, the overall complication rate related to both RT and SRS for CNs was only $3.2 \%$, which was lower than that for surgery. ${ }^{2}$ Also in a systematic review, Garcia et al. reported that the rate of serious complications for patients treated with SRS was 5.5\%, compared to $7.5 \%$ for those treated with conventional fractionated RT. ${ }^{36}$ Several radiationinduced complications following SRS, such as symptomatic peritumoral edema, radiation necrosis, intratumoral hemorrhage, malignant transformation, and alopecia, have been reported in the literature. ${ }^{8,13,16,17,25}$ Neovascularization of abnormal tissue after irradiation has been proposed as the possible cause of intratumoral hemorrhage, while some reports have suggested that hemorrhage from $\mathrm{CN}$ 


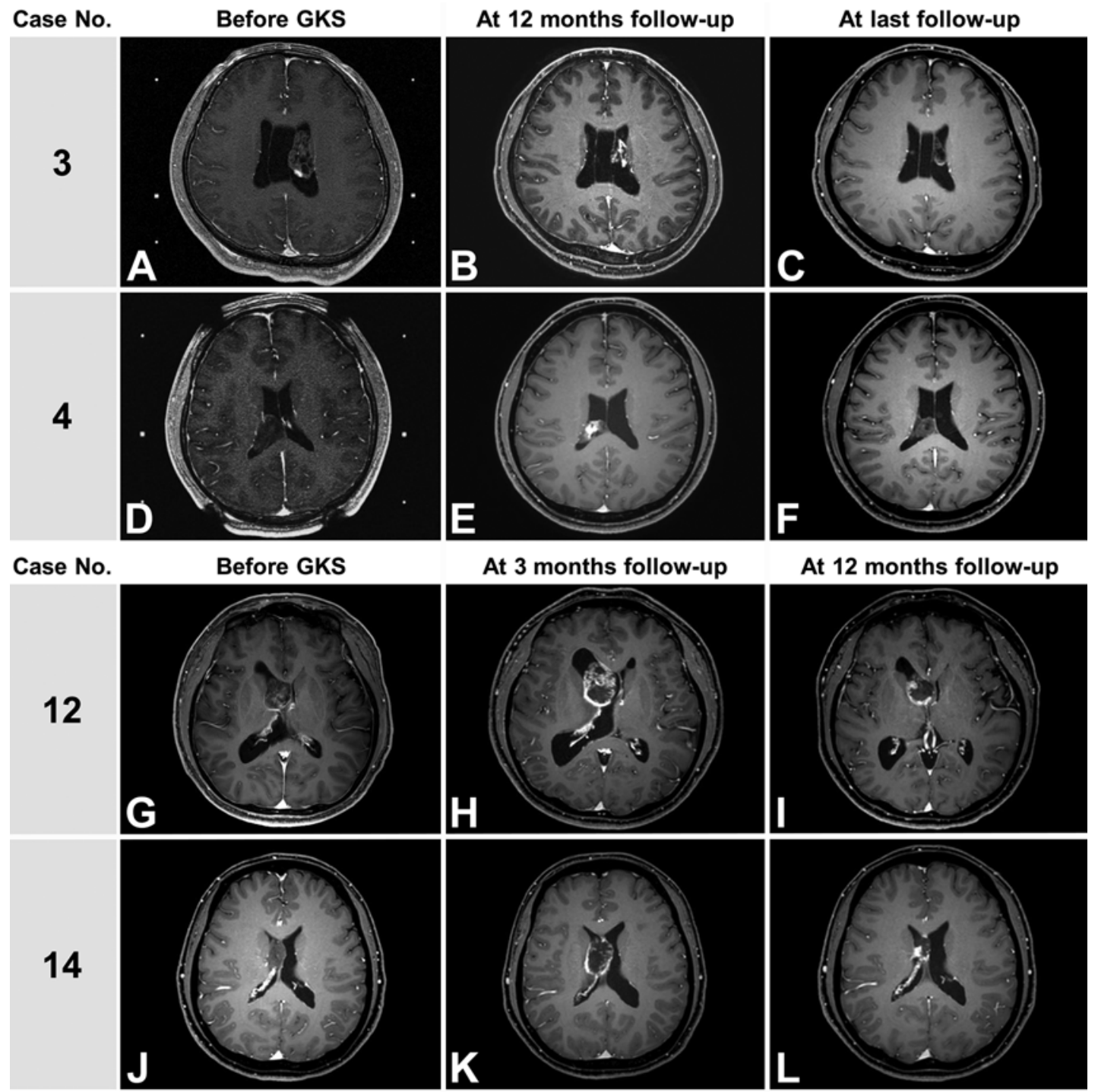

FIG. 2. Representative cases of tumor control and adverse radiation effect after GKRS for CNs. Case 3. A 36-year-old man presented with an incidentally found intraventricular lesion $\left(6.6 \mathrm{~cm}^{3}\right.$, A). GKRS was performed in a single session using $15 \mathrm{~Gy}$ (total of $30 \mathrm{~Gy}$ ) to the $50 \%$ isodose line. No new symptoms developed during the follow-up period (B), and the tumor volume was decreased to $1.5 \mathrm{~cm}^{3}$ at the last follow-up (C). Case 4 . A 38-year-old man with headache presented with an intraventricular lesion (3.7 $\mathrm{cm}^{3}$ ) without evidence of hydrocephalus (D). Single-session GKRS was performed with a prescription dose of 14 Gy (total of 28 $\mathrm{Gy}$ ) to the $50 \%$ isodose line (E). Although the tumor volume was decreased to $2.2 \mathrm{~cm}^{3}$ at the last follow-up (F), the patient still had intermittent headache, which may not have been attributable to the treated lesion. Case 12. A 59-year-old man presented with an incidentally found intraventricular lesion $\left(8.9 \mathrm{~cm}^{3}\right)$, and GKRS was performed in a single session using $14 \mathrm{~Gy}$ (a total of $28 \mathrm{~Gy}$ ) to the $50 \%$ isodose line (G). However, the patient later presented to the ED with severe headache, and MRI showed that the treated lesion had increased in size compressing the foramen of Monro with enlargement of the ipsilateral lateral ventricle $(\mathbf{H})$. Dexamethasone was immediately administered, and the patient was hospitalized for 7 days, after which his symptom greatly improved. The tumor volume was decreased to $6.7 \mathrm{~cm}^{3}$ at the last follow-up without additional symptoms (I). Case 14. A 49-year-old woman, who had initially undergone single-session GKRS with $15 \mathrm{~Gy}$ (total of $30 \mathrm{~Gy}$ ) to the $50 \%$ isodose line for an incidentally found intraventricular tumor $\left(2.5 \mathrm{~cm}^{3}\right)$, later presented to the ED with progressive headache $(\mathrm{J})$. MRI revealed an enlarged tumor without a change in the size of the lateral ventricle $(K)$. She was managed immediately with the administration of dexamethasone and was discharged after 4 days with improvement in her symptom. The tumor volume was decreased to $1.6 \mathrm{~cm}^{3}$ at the last follow-up (L).

may develop during its natural course, regardless of radiosurgery. ${ }^{25,43-45}$ Among the 14 patients enrolled in our study, there were 2 patients who had transient symptomatic edema 3 months after GKRS.

Limitations of the current study include not only the relatively small sample size, which is related to the rare- ness of $\mathrm{CN}$, but also the retrospective study design, lack of pathological confirmation in some cases, and heterogeneous prescription doses. However, we believe that our study, which is the largest case study on primary GKRS for $\mathrm{CN}$ to date, offers the possibility in clinical practice of discussing management strategies. Further investigation, 
TABLE 3. Literature survey of cases of GKS as a primary treatment for CNs

\begin{tabular}{|c|c|c|c|c|c|c|c|c|c|c|}
\hline \multirow[b]{2}{*}{ Authors \& Year } & \multirow{2}{*}{$\begin{array}{c}\text { No. of } \\
\text { Patients } \\
\text { (primary/total) }\end{array}$} & \multicolumn{2}{|c|}{ Diagnosis Before GKS } & \multirow[b]{2}{*}{$\begin{array}{c}\text { Tumor } \\
\text { Vol }\left(\mathrm{cm}^{3}\right)\end{array}$} & \multirow[b]{2}{*}{$\begin{array}{c}\text { Margin } \\
\text { Dose (Gy) }\end{array}$} & \multirow[b]{2}{*}{$\begin{array}{c}\text { FU } \\
(\mathrm{mos})\end{array}$} & \multicolumn{2}{|c|}{ Tumor Response } & \multirow[b]{2}{*}{$\begin{array}{c}\text { Distal } \\
\text { Recurrence }\end{array}$} & \multirow[b]{2}{*}{ Complications } \\
\hline & & Biopsy & $\begin{array}{l}\text { Radiological } \\
\text { Diagnosis }\end{array}$ & & & & Control & Progression & & \\
\hline $\begin{array}{l}\text { Tyler-Kabara et al., } \\
2001^{37}\end{array}$ & $2 / 4$ & 2 & 0 & $4.2,0.33$ & 15,20 & 40,42 & 2 & 0 & 0 & 0 \\
\hline Javedan et al., $2003^{42}$ & $1 / 1$ & 1 & 0 & NA & 18 & 25 & 1 & 0 & 0 & 0 \\
\hline Yen et al., $2007^{25}$ & $1 / 7$ & 1 & 0 & 4.7 & 20 & 120 & 1 & 0 & 0 & 0 \\
\hline Kim et al., $2007^{12}$ & $6 / 13$ & 0 & 6 & $7.7^{*}$ & $15^{*}$ & $42^{*}$ & 6 & 0 & 0 & 0 \\
\hline Genc et al., $2011^{38}$ & $4 / 22$ & 4 & 0 & $13.0 \dagger$ & $15.8 \dagger$ & $21^{*}$ & 4 & 0 & 0 & 0 \\
\hline Karlsson et al., $2012^{8}$ & $7 / 42$ & 1 & 6 & NA & NA & NA & NA & NA & NA & NA \\
\hline Kim et al., $2013^{9}$ & $10 \ddagger / 20$ & 2 & 8 & $8.2^{*}$ & $16^{*}$ & $80^{*}$ & 8 & 2 & 0 & 0 \\
\hline Present study & $14 / 14$ & 4 & 10 & $3.5^{\star}$ & $15^{*}$ & $25^{*}$ & 12 & 0 & 0 & $2 \S$ \\
\hline
\end{tabular}

NA = not available; primary = primary GKRS cases; total = primary and postoperative GKRS cases.

* Median value.

$\dagger$ Mean value.

$\ddagger$ Six of these patients were included in Kim et al., 2007.

$\S$ Transient.

together with long-term prospective follow-up to clarify the role of GKRS as a primary treatment modality in selected cases of $\mathrm{CN}$, is warranted.

\section{Conclusions}

The present study represents a single institution's experience with GKRS as a primary treatment for patients with $\mathrm{CN}$. All of the CNs in this study were well controlled without significant complication related to GKRS. We suggest that primary GKRS can be an effective and safe treatment option in the management of small- or medium-sized CNs, causing minimal or no neurological deficit. Long-term follow-up studies are necessary to validate the efficacy of GKRS and specify the indications for which GKRS can be chosen as an initial treatment for CNs.

\section{References}

1. Schild SE, Scheithauer BW, Haddock MG, et al. Central neurocytomas. Cancer. 1997;79(4):790-795.

2. Pan DH, Lee CC. The management of incidental central neurocytoma. Neurosurg Clin N Am. 2015;26(1):57-66.

3. Hassoun J, Gambarelli D, Grisoli F, et al. Central neurocytoma. An electron-microscopic study of two cases. Acta Neuropathol. 1982;56(2):151-156.

4. Hassoun J, Söylemezoglu F, Gambarelli D, et al. Central neurocytoma: a synopsis of clinical and histological features. Brain Pathol. 1993;3(3):297-306.

5. Kim DG, Kim JS, Chi JG, et al. Central neurocytoma: proliferative potential and biological behavior. J Neurosurg. 1996;84(5):742-747.

6. Tish S, Habboub G, Jones J, et al. The epidemiology of central and extraventricular neurocytoma in the United States between 2006 and 2014. J Neurooncol. 2019;143(1):123-127.

7. Bui TT, Lagman C, Chung LK, et al. Systematic analysis of clinical outcomes following stereotactic radiosurgery for central neurocytoma. Brain Tumor Res Treat. 2017;5(1):10-15.

8. Karlsson B, Guo WY, Kejia T, et al. Gamma Knife surgery for central neurocytomas. J Neurosurg. 2012;117(suppl):96-101.

9. Kim JW, Kim DG, Chung HT, et al. Radiosurgery for central neurocytoma: long-term outcome and failure pattern. $\mathrm{J} \mathrm{Neu-}$ rooncol. 2013;115(3):505-511.

10. Rades D, Schild SE. Value of postoperative stereotactic radiosurgery and conventional radiotherapy for incompletely resected typical neurocytomas. Cancer. 2006;106(5):11401143.

11. Kim DG, Paek SH, Kim IH, et al. Central neurocytoma: the role of radiation therapy and long term outcome. Cancer. 1997;79(10):1995-2002.

12. Kim CY, Paek SH, Jeong SS, et al. Gamma knife radiosurgery for central neurocytoma: primary and secondary treatment. Cancer. 2007;110(10):2276-2284.

13. Yamanaka K, Iwai Y, Shuto T, et al. Treatment results of Gamma Knife radiosurgery for central neurocytoma: report of a Japanese multi-institutional cooperative study. World Neurosurg. 2016;90:300-305.

14. Rades D, Fehlauer F, Lamszus K, et al. Well-differentiated neurocytoma: what is the best available treatment? Neuro Oncol. 2005;7(1):77-83.

15. Paek SH, Han JH, Kim JW, et al. Long-term outcome of conventional radiation therapy for central neurocytoma. $J$ Neurooncol. 2008;90(1):25-30.

16. Martín JM, Katati M, López E, et al. Linear accelerator radiosurgery in treatment of central neurocytomas. Acta Neurochir(Wien). 2003;145(9):749-754.

17. Matsunaga S, Shuto T, Suenaga J, et al. Gamma knife radiosurgery for central neurocytomas. Neurol Med Chir (Tokyo). 2010;50(2):107-113.

18. Anderson RC, Elder JB, Parsa AT, et al. Radiosurgery for the treatment of recurrent central neurocytomas. Neurosurgery. 2001;48(6):1231-1238.

19. Bertalanffy A, Roessler K, Koperek O, et al. Recurrent central neurocytomas. Cancer. 2005;104(1):135-142.

20. Chen MC, Pan DH, Chung WY, et al. Gamma knife radiosurgery for central neurocytoma: retrospective analysis of fourteen cases with a median follow-up period of sixty-five months. Stereotact Funct Neurosurg. 2011;89(3):185-193.

21. Chen KP, Lee CC, Liao CL, et al. Upfront Gamma Knife surgery for giant central neurocytoma. World Neurosurg. 2017;97:751.e15-751.e21.

22. Cobery ST, Noren G, Friehs GM, et al. Gamma knife surgery for treatment of central neurocytomas. Report of four cases. $J$ Neurosurg. 2001;94(2):327-330.

23. Hara M, Aoyagi M, Yamamoto M, et al. Rapid shrinkage of 
remnant central neurocytoma after gamma knife radiosurgery: a case report. J Neurooncol. 2003;62(3):269-273.

24. Rades D, Schild SE. Treatment recommendations for the various subgroups of neurocytomas. J Neurooncol. 2006;77(3):305-309.

25. Yen CP, Sheehan J, Patterson G, Steiner L. Gamma knife surgery for neurocytoma. J Neurosurg. 2007;107(1):7-12.

26. Niiro T, Tokimura $H$, Hanaya R, et al. MRI findings in patients with central neurocytomas with special reference to differential diagnosis from other ventricular tumours near the foramen of Monro. J Clin Neurosci. 2012;19(5):681-686.

27. Snell JW, Sheehan J, Stroila M, Steiner L. Assessment of imaging studies used with radiosurgery: a volumetric algorithm and an estimation of its error. Technical note. J Neurosurg. 2006;104(1):157-162.

28. Da Silva AN, Nagayama K, Schlesinger D, Sheehan JP. Early brain tumor metastasis reduction following Gamma Knife surgery. J Neurosurg. 2009;110(3):547-552.

29. Harrison G, Kano H, Lunsford LD, et al. Quantitative tumor volumetric responses after Gamma Knife radiosurgery for meningiomas. J Neurosurg. 2016;124(1):146-154.

30. McTyre E, Helis CA, Farris M, et al. Emerging indications for fractionated Gamma Knife radiosurgery. Neurosurgery. 2017;80(2):210-216.

31. Kim JW, Kim DG, Kim IK, et al. Central neurocytoma: longterm outcomes of multimodal treatments and management strategies based on 30 years' experience in a single institute. Neurosurgery. 2013;72(3):407-414.

32. Imber BS, Braunstein SE, Wu FY, et al. Clinical outcome and prognostic factors for central neurocytoma: twenty year institutional experience. J Neurooncol. 2016;126(1):193-200.

33. Nakamura A, Kano H, Niranjan A, Lunsford LD. Radiosurgery for central neurocytoma. Prog Neurol Surg. 2019;34:232-237.

34. Park HK, Steven DC. Stereotactic radiosurgery for central neurocytoma: a quantitative systematic review. J Neurooncol. 2012;108(1):115-121.

35. Sharma MC, Deb P, Sharma S, Sarkar C. Neurocytoma: a comprehensive review. Neurosurg Rev. 2006;29(4):270-285.

36. Garcia RM, Ivan ME, Oh T, et al. Intraventricular neurocytomas: a systematic review of stereotactic radiosurgery and fractionated conventional radiotherapy for residual or recurrent tumors. Clin Neurol Neurosurg. 2014;117:55-64.

37. Tyler-Kabara E, Kondziolka D, Flickinger JC, Lunsford LD. Stereotactic radiosurgery for residual neurocytoma. Report of four cases. J Neurosurg. 2001;95(5):879-882.

38. Genc A, Bozkurt SU, Karabagli P, et al. Gamma knife radiosurgery for cranial neurocytomas. J Neurooncol. 2011;105(3):647-657.

39. Bertalanffy A, Roessler K, Dietrich W, et al. Gamma knife radiosurgery of recurrent central neurocytomas: a preliminary report. J Neurol Neurosurg Psychiatry. 2001;70(4):489493.

40. Kim CY, Paek SH, Kim DG. Linear accelerator radiosurgery for central neurocytoma: a case report. J Neurooncol. 2003;61(3):249-254.

41. Pollock BE, Stafford SL. Stereotactic radiosurgery for recurrent central neurocytoma: case report. Neurosurgery. 2001;48(2):441-443.

42. Javedan SP, Manwaring K, Smith KA. Treatment of posterior third ventricular central neurocytoma with endoscopic biopsy, endoscopic third ventriculostomy and stereotactic radiosurgery. Minim Invasive Neurosurg. 2003;46(3):165-168.

43. Gallina P, Mouchaty H, Buccoliero AM, Di Lorenzo N. Haemorrhagic central neurocytoma of the fourth ventricle. Acta Neurochir (Wien). 2005;147(11):1193-1194.

44. Smets K, Salgado R, Simons PJ, et al. Central neurocytoma presenting with intraventricular hemorrhage: case report and review of literature. Acta Neurol Belg. 2005;105(4):218-225.

45. Terakawa Y, Tsuruno T, Ishibashi K, et al. Central neurocytoma presenting with massive hemorrhage leading to comacase report. Neurol Med Chir (Tokyo). 2010;50(2):139-143.

\section{Disclosures}

The authors report no conflict of interest concerning the materials or methods used in this study or the findings specified in this paper.

\section{Author Contributions}

Conception and design: Lee, Jeon. Acquisition of data: Jeon. Analysis and interpretation of data: Lee, Jeon. Drafting the article: Jeon. Critically revising the article: all authors. Reviewed submitted version of manuscript: all authors. Approved the final version of the manuscript on behalf of all authors: Lee. Study supervision: Lee.

\section{Correspondence}

Jung-Il Lee: Samsung Medical Center, Sungkyunkwan University School of Medicine, Seoul, Republic of Korea. jilee@skku.edu. 